de Santiago en el proceso de revitalización y recuperación del casco antiguo. Para ello, la mejor vía es el establecimiento de campañas específicas de difusión en los medios profesionales de comunicación, centros escolares, lugares de reunión, etc. de exposiciones, publicaciones, conferencias, mesas redondas, concursos en las escuelas y similares, para mostrar tanto un pasado histórico brillante como un presente delicado $y$, sobre todo, un futuro atractivo y posible.

La historia de la persona va indisolublemente ligada al escenario donde desarrolla su vida, y la pérdida de parte de este escenario supone la desaparición de parte de su infancia o su pasado.

- Establecimiento de una necesaria coordinación interadministración que optimice, tanto el empleo de los recursos disponibles, como la fluidez del desarrollo del proceso.

- Potenciar el papel de la Corporación para el Desarrollo de Santiago como Organismo impulsor del proceso y coordinador de los actores y recursos necesarios.
En el convencimiento de que este proceso es realizable e irreversible, es necesario abordar una primera experiencia piloto que demuestre su viabilidad e incentive la continuación del mismo.

Al respecto, es necesario considerar que las medidas que se toman además de las urbanísticas, han de buscar revitalizar y potenciar la actividad socioeconómica de las áreas más deprimidas.

También, que la inversión ha de ser choque, concentrada en espacio y tiempo, para que efectúe un efecto multiplicador y dinamice la inversión privada.

Establecer relaciones con Organismo Internacionales relacionados tanto en la Protección del Patrimonio/UNESCO, de la Corporación Internacional de Vivienda, Medio Ambiente, etc., buscando su apoyo institucional para este proceso.

Verónica Serrano Madrid

Especialista en Rehabilitación del Patrimonio

\section{CLASIFICACIÓN SISTEMÁTICA GENERAL PARA LA CONSERVACIÓN Y RESTAURACIÓN DE BIENES MUEBLES}

Se publica a continuación el comentario que, a raíz del Editorial del Boletín Informativo n. ${ }^{\circ}$, nos hiciera llegar el Sr. Decano del Colegio Oficial de Doctores y Licenciados en Bellas Artes y Profesores de Dibujo de Sevilla.

Estudiar y analizar el contenido pormenorizado de la Clasificación Sistemática para la Conservación y Restauración de Bienes Muebles significa reflexionar sobre la valoración tan profunda y completa que ha llevado a cabo la Dirección General de Bienes Culturales a través del Servicio de Conservación y Restauración.

Como Máxima representación del Colectivo de los profesionales de la Conservación y Restauración de Bienes Muebles de Andalucía, englobados en el Ilustre Colegio Oficial de Doctores y Licenciados en Bellas Artes y Profesores de Dibujo debo recapacitar sobre la significación de este ordenamiento en las materias de los Bienes Muebles.

Partimos del principio de una profesión cuyo reconocimiento e importancia es considerada cada vez más en el nivel social y profesional que se merece. Partimos de un reconocimiento técnico y científico necesario para el estudio de los Bienes Culturales. Partimos como una profesión integrante en grupos interdisciplinares o como directores y coordinadores de los mismos. Se aleja cada vez más el concepto artesanal para profundizar en el estudio y análisis del material a tratar.

La Consejería de Cultura y Medio Ambiente de la Junta de Andalucía, pionera de la legislación, normalización y ordenamiento de la Conservación y Restauración de los Bienes Muebles en toda España, toma conciencia de las necesidades y exigencias de este Colectivo Profesional.

Ya en la Ley 1/1991 de Patrimonio Histórico de Andalucía se crea la obligación de un Proyecto de Conservación ante una intervención en el Patrimonio Histórico de Andalucía. Se crean unas pautas de contenido de ese Proyecto que más adelante se van a desarrollar en el Reglamento de Conservación y Restauración.
Los Primeros Proyectos de Conservación y Restauración de los Bienes Muebles, con un profundo desarrollo, parten de Andalucía. Pero ser pionera en la materia significa ir tropezando en todos los vacíos que se encuentren en el camino.

Era necesaria la creación de un banco de Precios, imprescindible para la regulación de precios y tarifas de materias y materiales que el profesional va a desarrollar. Aún en la semejanza de criterios, aún en la semejanza de materiales a emplear, aún en la semejanza de necesidades en la intervención en los Bienes Muebles, faltaba una ordenación de ideas y conceptos, puesto que los Proyectos desarrollados por los profesionales son muy dispares entre sí.

La idea de la realización de un Banco de Precios por parte del Departamento de Bienes Muebles del Servicio de Conservación y Restauración que de homogeneidad y ofrezca pautas de comportamientos similares es, sin duda, una acción inmejorable. Pero el Banco de Precios, al igual que su homólogo Banco de Precios de la Construcción, parte de la necesidad de realizar una Clasificación Sistemática General que garantice todas aquellas posibilidades técnicas, científicas y complementarias que un Conservador-Restaurador puede encontrar a la hora de realizar un Proyecto.

Reflexionando sobre el contenido, y siendo bastante coherente en la materia, puedo decir que es la Clasificación más exhaustiva y completa que se podía desarrollar en este tema. Imagino que es mejorable en el futuro, ya que se trata de una Clasificación Sistemática bastante abierta. La labor realizada por los técnicos del Departamento de Bienes Muebles y por su coordinador Rafael Lucas Ruiz es de elogio. La claridad con que se desarrolla, el ordenamiento, la división de los Capítulos, Subcapítulos y Apartados, las claves y numeración con las que se definen hacen que su contenido tanga buena asimilación y buen entendimiento.

Esperemos que todos los profesionales tengamos acceso a esta Clasificación Sistemática, que sin duda será bien aceptada por nuestro Colectivo y que sea el principio del tan esperado Banco de Precios para la Conservación y Restauración de los bienes Muebles.

Mauricio J. López Madroñero Decano del Colegio Oficial de Doctores y Licenciados en Bellas Artes de Sevilla 